\title{
LA COHORTE II DE CABALLERÍA DE ASTURES Y GALAICOS
}

\author{
NARCISO SANTOS YANGUAS \\ Universidad de Oviedo
}

\section{Resumen}

La cohors II Asturum et Callaecorum sería reclutada en los años finales de Augusto o en los primeros de Tiberio, siendo adiestrados sus primeros soldados en el campamento de la legión X Gemina (o tal vez en el de la VI Victrix).

Los diplomas militares confirman que su historia se relacionaría con el territorio panónico, donde al parecer ocuparía los campamentos de Bantina, Lugio y Brigetio.

Entre sus integrantes conocemos a un prefecto y un soldado, habiéndose producido la desaparición de dicha unidad no antes de finales del siglo II.

\section{Palabras clave}

Epigrafía, historia militar, astures, galaicos, cohorte, romanización.

\section{Abstract}

The cohors II Asturum et Callaecorum was recruited in the last years of the Augustan period or during the early years of Tiberian rule, their first soldiers being most probably trained in the camp of the legio X Gemina (or in VI Victrix).

Its history, as military diplomas show, is linked to Panonian territory, where it occupied the following camps: Bantina, Lugio and Brigetio.

A prefect and a soldier are among its known members. It disappeared as a cohors in the final years of the 2 nd century.

\section{Keywords}

Epigraphy, military history, astures, callaeci, cohors, romanization. 


\section{INTRODUCCIÓN}

En el marco de la estructura general del ejército de César la táctica militar básica estaría relacionada con la cohorte, caracterizada por su capacidad de maniobra, por lo que dispondría de un lugar definido en el marco de los cuerpos legionarios, de los que dependerían obviamente ${ }^{1}$.

La forma más eficaz de hacer frente a los indígenas septentrionales y su táctica militar consistente en la guerra de guerrillas (ataques inesperados por grupos de soldados en número reducido ${ }^{2}$ ), la constituiría sin duda la cohorte cesariana, ya que, además de disponer de varios centenares de soldados de infantería, contaría con un grupo de jinetes frente a los ataques de las comunidades del Norte peninsular en el suelo más abrupto e intrincado ${ }^{3}$.

Por ello tanto las alas como, de forma especial, las cohortes pasarían a ocupar un lugar de privilegio como tropas dependientes de las legiones, contribuyendo además a un mejor control del suelo provincial ${ }^{4}$.

En este sentido las propias condiciones naturales de organización militar de los indígenas septentrionales favorecería su inclusión en los cuerpos de ejército romano, cuyos objetivos eran similares a sus formas tradicionales de actuación frente a un enemigo exterior.

De esta manera la presencia de astures y galaicos en las filas militares romanas se realizaría a través de reemplazos continuados, aunque solo en una primera fase podemos pensar en reclutamientos forzosos, puesto que pocos años después se convertirían en voluntarios ${ }^{5}$.

Tales levas estaban orientadas hacia el incremento de los destacamentos de tropas auxiliares, así como, en ocasiones menos frecuentes, a reemplazar a algunos soldados de los cuerpos legionarios, licenciados o muertos en servicio.

${ }^{1}$ Caes., B. Gall. 5.33.1 y 35.1. Durante el Imperio numerosas inscripciones contienen la frase legio... et auxilia eius, lo que constituye un argumento irrefutable a favor de la conexión existente entre los cuerpos de tropas auxiliares y las legiones: cf., por ejemplo, CIL VIII.2637 = ILS 342, fechado en el año 158 y referido a la legión III Augusta y sus tropas auxiliares, o el de una inscripción de Pannonia de tiempos de Galieno, en la que se mencionan "los destacamentos de las legiones germánicas y británicas con sus tropas auxiliares" (CIL III.3228 = ILS 546).

2 A.GARCÍA y BELLIDO, "Bandas y guerrillas en las luchas con Roma”, Hispania 5 (1945) 547 y ss. = Conflictos y estructuras sociales en la Hispania antigua, Madrid 1977, pp.13 y ss.

${ }^{3}$ I.KERTESZ, “The Roman Cohort Tactics. Problems of Development", Oikoumene 1 (1976) 89 y ss.

${ }^{4}$ Más detalles en P.A.HOLDER, Studies in the Auxilia of the Roman Army from Augustus to Trajan, Oxford 1980.

5 G.R.WATSON, “Conscription and Volunteering in the Roman Imperial Army”, SCI 1 (1974) 90 y ss. 
Así pues, al darse por finalizada la anexión del territorio septentrional ibérico, el Estado romano, con el fín de facilitar el dominio de esas poblaciones rebeldes y asegurarse en el período inmediato los ingresos que las minas podían proporcionarle, basará su política en el control y ocupación organizada del mismo (tratando de hacer posible la presencia de los indígenas astures, así como cántabros y galaicos, en su ejército).

Los más jóvenes de estos indígenas serían reclutados con vistas a su adiestramiento en el marco de alguna de las legiones que, ya como ejército de ocupación ${ }^{6}$, tendrían su acuartelamiento en territorio astur-galaico, bien la VI Victrix bien la $\mathrm{X}$ Gemina (CIL IX.3610 = ILS 2707 como ejemplo) ${ }^{7}$.

Pero, junto a estos soldados (tal vez reducidos en cuanto a su número), utilizados en la complementación de los destacamentos romanos de ocupación, abundantes inscripciones se refieren a un elevado conjunto de elementos auxiliares procedentes del Noroeste peninsular, integrantes tanto de las alas como de las cohortes portadoras de étnicos indígenas (astures, galaicos, astures y galaicos, lucenses, bracaraugustanos...), que en su origen serían alistados entre los miembros de dichas comunidades $^{8}$.

\section{AUGUSTO Y EL EJÉRCITO ROMANO}

En las décadas inmediatas a la pacificación del cuadrante nordoccidental hispano (y en parte coincidiendo ya con los años de las guerras astur-cántabras) tendría lugar la formación de una amplia línea fronteriza en el Rín, Panonia y Dalmacia.

La necesidad de abastecer de militares este extenso limes obligaría al primer emperador romano a recurrir en innumerables ocasiones a los componentes de las nuevas poblaciones incorporadas al Imperio, que serían empleados como cuerpos de tropas auxiliares ${ }^{9}$.

\footnotetext{
${ }^{6}$ Más detalles en N.SANTOS, "El final de las guerras astur-cántabras y la desmilitarización del ejército romano en territorio de los astures", Studia Historica (en prensa).

${ }^{7}$ No muy lejos estaría acampada la legión IIII Macedónica. Cf. C.PÉREZ GONZÁLEZ, "Pisoraca (Herrera de Pisuerga): Urbanismo militar y civil de época romana", Los orígenes de la ciudad en el Noroeste hispánico, Lugo 1999, pp.535 y ss.

${ }^{8}$ A este respecto sobresalen los diplomas militares hallados en las diferentes provincias del Imperio próximas a las líneas fronterizas y que nos permiten analizar la importancia militar de estos ejércitos.

${ }^{9}$ Más detalles en J.M.ROLDÁN, "La conquista del Norte de Hispania y la participación de los astures en el ejército imperial romano", Lancia 1 (1983) 119 y ss.
} 
Entre el conjunto de los nuevos militares del ejército de Augusto destacan los procedentes de las regiones cantábricas (galaicos, astures y cántabros), cuya aportación a la máquina militar romana se prolongaría durante toda la dinastía julioclaudia (y en menor medida durante la flavia), según se deduce de las unidades de tropas auxiliares de origen hispano conocidas, así como del momento de su configuración y de sus lugares de acuartelamiento ${ }^{10}$.

Se comprende así la presencia de cohortes mixtas integradas por elementos astures y galaicos, de las que conocemos al menos dos y cuyo origen parece datarse en los años finales de la época augustea o ya durante las primeras décadas de los emperadores de la dinastía julio-claudia.

En cualquier caso la situación se correspondería con la primera fase de organización del nuevo territorio anexionado, hecho que parece coincidir perfectamente con las referencias recogidas por Estrabón con respecto a los 3 distritos del Noroeste peninsular ${ }^{11}$, dos de los cuales estarían militarizados (uno de ellos con dos legiones -la VI Victrix y X Gemina- y el otro con una sola -la IIII Macedónica-, mientras que el tercero permanecería sin tropas acuarteladas en el mismo).

Algunos investigadores contemporáneos han pretendido que el escritor griego describe dicha organización territorial de acuerdo con una división en diócesis, para lo que creemos que no existe base alguna; en realidad parece más lógico creer en una simple división (distribución territorial) de carácter estratégico-militar, de acuerdo con la cual a cada uno de los cuerpos de tropas legionarias le habría sido asignada una zona de vigilancia concreta, en la que se realizaría a un mismo tiempo el reclutamiento de los indígenas correspondientes ${ }^{12}$.

\section{ORIGEN, DENOMINACIÓN Y NOMENCLATURA}

La configuración de cuerpos auxiliares de infantería mezcla de elementos étnicos procedentes de dos poblaciones distintas se produciría solamente cuando ambos colectivos habitaban regiones contiguas, como sucede en el caso de la cohorte II de astures y galaicos.

No resulta posible datar con precisión absoluta el momento de alistamiento, formación y configuración de esta unidad de tropas auxiliares.

\footnotetext{
${ }^{10}$ Más detalles en J.M.ROLDÁN, Hispania y el ejército romano. Contribución a la historia social de la España antigua, Salamanca 1974.

${ }^{11}$ Geografía 3.4.20.

12 G.R.WATSON, "Conscription and Voluntary Enlistment in the Roman Army", PACA 16 (1982) 46 y ss.
} 
Al parecer el reclutamiento de los elementos integrantes de estas comunidades septentrionales hispanas para su inclusión en el ámbito militar romano en el marco de la cohorte II de astures y galaicos tendría lugar en los años finales de Augusto o primeros momentos de Tiberio, algún tiempo después de la fecha en que sería alistada la cohorte I de astures y galaicos ${ }^{13}$.

Dicho destacamento militar, del que formarían parte elementos astures de procedencia indeterminada (transmontanos y/o augustanos), tal vez en mayor número de los segundos al estar mezclados con sus vecinos reclutas galaicos, serían adiestrados en el campamento de la legión VI Victrix (o en el de la X Gemina).

El carácter de equitata (tropas de infantería mezcladas con algunos significativos elementos de caballería) se desprende con facilidad del diploma militar fechado en el año $145^{14}$, a través del cual tenemos conocimiento de un tal ...entis f(lius) Iustus, eq(ues), ciudadano romano.

\section{HISTORIA DE LA UNIDAD}

La existencia de este cuerpo de tropas de astures y galaicos aparece constatada en un conjunto de diplomas militares, a pesar de que, frente a ello, ningún documento (ni epigráfico ni de otro tipo) se refiera a alguno de los soldados integrados en el mismo ${ }^{15}$.

Precisamente tomando como base dichos diplomas militares sabemos que la historia de la cohorte II de caballería de astures y galaicos se circunscribiría a un territorio muy concreto, el correspondiente a las provincias romanas de Panonia.

A este respecto las primeras noticias de la misma se fechan el 13 de junio del año $80^{16}$, e igualmente poco después otro documento oficial de estas mismas características (correspondiente al día 5 de septiembre del año 85) nos documenta su presencia en el mismo territorio panónico ${ }^{17}$.

De ello es posible deducir que la cohorte II de astures y galaicos se hallaría ya asentada de manera definitiva y con campamento estable en la provincia de Panonia, de cuyo ejército de ocupación formaría parte, durante la época de los emperadores flavios.

\footnotetext{
${ }^{13}$ Sobre la creación y dislocaciones de esta unidad de tropas auxiliares de astures y galaicos remitimos, entre otros, a N.SANTOS, "La cohorte I de astures y galaicos en territorio norteafricano", Gerión 22 (2004) 245 y ss.

14 CIL XVI.91.

15 J.M.ROLDÁN, Hispania y el ejército romano, p.94.

16 CIL XVI.26.

17 CIL XVI.31.
} 
Igualmente conocemos que dicha estancia se prolongaría durante los años de Trajano, de acuerdo con lo que se desprende del diploma militar que se fecha el día 2 de julio del $110^{18}$.

A continuación se enrolaría entre las unidades de tropas auxiliares correspondientes a Panonia Inferior tras la división del antiguo territorio panónico en dos, hecho que tendría lugar en el año 106 y que se produciría inmediatamente después de la finalización de la guerra dácica ${ }^{19}$.

Desde esa fecha hasta los años 139/145 no disponemos de ningún otro testimonio acerca de su existencia, a pesar de lo cual no parece lógico pensar que sería dislocada de dicho territorio, y menos todavía si tenemos en cuenta que los cuerpos de tropas asentados en Panonia Inferior apenas experimentarían traslados a lo largo de toda su historia ${ }^{20}$.

Todo un conjunto de diplomas militares en los que aparece mencionado este cuerpo de tropas auxiliares de astures y galaicos nos testimonia su presencia en la provincia antes mencionada a lo largo de las décadas siguientes: en primer término destaca el fechado en $139 / 145^{21}$, cuyo texto, muy fragmentado, ha tenido que ser reconstruido en gran medida.

Junto a éste sobresalen los documentos correspondientes al año $148^{22}$, así como los que en un principio se habían datado el 27 de diciembre de una franja temporal entre los años 151 y $160^{23}$.

De unos años antes de esa última fecha, en concreto del 8 de febrero del 157, han aparecido en Lussonium (actual Dunakömlöd) dos diplomas militares nuevos: el primero de ellos, del que se conservan varios fragmentos ennegrecidos por el fuego, fue descubierto en las proximidades de un campamento de tropas auxiliares, en el que se refleja, tanto en su parte externa como interna, la presencia de la cohors II Asturum et Callaecorum ${ }^{24}$.

El contenido de la cara externa de este documento nos refleja las unidades militares que formaban parte del ejército romano destacado en la provincia panónica ${ }^{25}$ :

${ }^{18}$ CIL XVI.164. Cf. J.SZILAGYI, "Roman Garrisons stationed at the Northern Pannonien-Quad Frontier-Sectors of the Empire", AArchHung 2 (1952) 189 y ss.

${ }^{19}$ Más detalles en R.SYME, "Governors of Pannonia Inferior", Historia 14 (1965) 342 y ss.

${ }^{20}$ A.RADNOTI y L.BARKOCZI, "The Distribution of Troops in Pannonia Inferior during the 2nd. Century A.D.", AArchHung 1 (1951) 191 y ss.

${ }^{21}$ CIL XVI.91.

${ }^{22}$ CIL XVI.179 y 180.

${ }^{23}$ CIL XVI.112 y 113. Cf. J.M.ROLDÁN, Hispania y el ejército romano, p.95.

${ }^{24}$ Para más detalles remitimos a Z.VISY en A Szekszárdi Béri Balog Adám Muzeum Évokönyne 10-11 (1979-1980) 61 y ss.

${ }^{25}$ A.E. 1983, n1 784, pp.222-223. 
Imp(erator) Caes(ar) diui Hadriani f(ilius) d[iui Traiani]/ Parthic(i) nep(os) diui Neruae [pronep(os)]/T(itus) Aelius Hadrianus Antoni[nus A[ug(ustus) Pi]/ us pont(ifex) max(imus) tr(ibunicia) pot(estate) XIX imp(erator) [II co(n)s(ul) IIII p(ater) p(atriae)] equitibus et peditibus qui $m[$ ili[t(auerunt) in alis V]/ quae appellant[ur I Thr(acum) vet(erana) sag(ittariorum) et I c(iuium) R(omanorum)]/ et I praetor(ia) c(iuium) R(omanorum) et I Fl(avia) Aug(usta) [Brit(annica) (milliaria)]/ et I Aug(usta) Itur(aeor)um et cohortibus XIII I Al[p(inorum) eq(uitata)]/ et III Batavor(um) et I Thr(acum) Germ(anica) et/ I [Alp(inorum) ped(itata)/ et] I Noric(um) et III Lusit(anorum) et II Ast(urum) et [Call(aecorum)/ et] VII Breuc(orum) et I Lusit(anorum) et II Aug(usta) Thr[ac(um)/ et I] Montan(orum) et I Camp(anorum) vol(untariorum) et I Thr(acum) c(iuium) R(omanorum)/ [et s]unt in Pannonia inferior(e) sub/ [Ial]lio Basso leg(ato) quinq(ue) et viginti/ [ite]m classic(is) sex et vigint(i) stipend(iis)/ [e]merit(is) $\operatorname{dimis[s(is)]~honest(a)~missio[ne/~q]uorum~nomin(a)~[su]bscrip[t(a)/~[ci]vitatem~}$ Roma[nam] q[ui eo]rum/ [n]on haber(ent) de[dit et c]onub(ium) c] um u[xo/r]ibus quas t[unc habuiss(ent) cum] es[t ci/ vi]tas $i(i) s$ da[t(a) aut cum i(i)s quas postea duxiss(ent)/ d]umtaxat singulis a(nte) d(iem) VI id(us) [Feb(ruarias)]/ M(arco) Civica Barbaro M(arco) Metilio Regulo co(n(s(ulibus)/ coh(ortis) I Thrac(um) Germ(anicae) cui prae(e)st/ [C(aius)] Turpilius Verecundus/ ex pedite/ Culso Ateduni fil(io) Eravisco/ et Ve[r]uedae Tessimari fil(iae) uxo(ri) eiu(s) Era(viscae)/ descript (um) et recognitum.... ${ }^{26}$.

El único defecto común a ambos textos (partes externa e interna del diploma) lo constituye la consignación errónea de la tribunicia potestas atribuida al emperador Antonino, puesto que no se trata de la XIX sino de la XX (10 de diciembre de 156 a 9 de diciembre de 157).

Por su parte el otro diploma militar de la fecha que estamos reseñando ( 8 de febrero de 157) constituye un documento completo, encontrado junto con el anterior $^{27}$ y cuyo contenido es totalmente igual (tanto en su exterior como en su interior) excepto en lo referente a las personas objeto de la promoción social y la adquisición de los derechos inherentes al licenciamiento del ejército ${ }^{28}$.

Al año siguiente (27 de diciembre de 158) corresponden precisamente otros dos diplomas (CIL XVI.112 y 113), cuya datación no se había ajustado al contenido del texto de ambos: el primero de ellos, revisado igualmente hace un par de décadas ${ }^{29}$,

\footnotetext{
${ }^{26}$ La parte interna recoge prácticamente el mismo contenido, describiéndose las mismas unidades de tropas auxiliares.

${ }^{27}$ Z.VISY en A Szekszárdi Béri Balog Adám Muzeum Évokönyne 10-11 (1979-1980) 63 y ss.

${ }^{28}$ A.E. 1983 , n1 785, pp.224-225.

${ }^{29}$ Z.VISY en A Szekszárdi Béri Balog Adám Muzeum Évokönyne 10-11 (1979-1980) 71 y ss.
} 
nos documenta la presencia de los mismos destacamentos de tropas auxiliares en Panonia Inferior, entre los que se hallaba la cohors II Asturum et Callaecorum ${ }^{30}$, mientras que el segundo, en estado mucho más fragmentado, recoge igualmente los cuerpos militares acuartelados en la provincia romana mencionada ${ }^{31}$.

La fecha final de referencia de que disponemos en la actualidad se corresponde con el diploma militar datado el 5 de mayo del año $167^{32}$.

De entre todos estos documentos cabe destacar los fechados en el año 148 por el hecho de no aparecer mencionada en ellos la cohors II Asturum et Callaecorum sino la cohors II Nerviorum et Callaecorum, lo que se interpretó desde el momento mismo de su descubrimiento como un error ${ }^{33}$.

\section{ACUARTELAMIENTO Y SOLDADOS}

Esta unidad de tropas de astures y galaicos no cuenta con referencias claras acerca de su lugar (o lugares) de acampada; ahora bien, si consideramos que para algunos investigadores ${ }^{34}$ desde los años del emperador Antonino Pío los cuerpos auxiliares correspondientes a cada provincia, tal y como aparecen registrados en los diferentes diplomas militares, no estarían clasificados de acuerdo con la numeración que tenían habitualmente sino con su emplazamiento a lo largo del limes que se les había asignado, habría que adjudicar a dicha cohorte el campamento de Lugio, actual Donaszeskö.

Sin embargo, esta hipótesis no parece tener aplicación en nuestro caso, puesto que dicho enclave constituiría el acuartelamiento de la cohors VII Breucorum, de acuerdo con los abundantes fragmentos de tégulas correspondientes a dicho cuerpo militar ${ }^{35}$.

A pesar de estos inconvenientes, algunas características topográficas del lugar, unido a su importancia desde el punto de vista estratégico, así como al hecho de haberse constatado la existencia de campamentos dobles en otras regiones simila-

\footnotetext{
${ }^{30}$ A.E. 1983 , n1 787a, p.226.

${ }^{31}$ A.E. $1983, \mathrm{n} 1787$ b, p.227.

${ }^{32}$ CIL XVI.123. Más detalles en J.FITZ, "Die Militärdiplome aus Pannonia Inferior in der 2. Hälfte des II. Jahrhunderts", AAntHung 7 (1959) 421 y ss.

${ }^{33}$ CIL XVI.179 y 180. Cf. A.BALIL, "Alas y cohortes astures en el ejército romano", Libro homenaje al conde de la Vega del Sella, Oviedo 1956, 1, p.311.

${ }^{34}$ Como por ejemplo A.RADNOTI ("Zur Dislokation der Auxiliartruppen in den Donauprovinzen”, Limes-Studien, Basilea 1959, pp.134 y ss.).

35 J.BOGAERS, “Cohortes Breucorum”, BROB 19 (1969) 27 y ss.
} 
res del Imperio, pueden llevarnos a aceptar un asentamiento común de ambos destacamentos de tropas.

Es posible igualmente que, en un período anterior, de acuerdo con el testimonio de una tégula hallada en Bantina, estuviera acampada en este lugar, situado más al sur, donde sería sustituida en los años siguientes por la cohors II Augusta Thracum $^{36}$.

Por otro lado, al margen de las referencias aportadas por los diplomas militares, podemos conocer algo más de la historia de la cohorte II de los astures y galaicos en Panonia Inferior a través de una serie de tégulas en las que se refleja su presen$\operatorname{cia}^{37}$.

La procedencia de las mismas se corresponde con Bantina, Rittium y Brigetio respectivamente, lo que ha permitido situar los lugares de acampada de dicho cuerpo de tropas en los enclaves mencionados, aunque tal vez en alguna de las ocasiones fuese únicamente de manera transitoria ${ }^{38}$.

Finalmente, por lo que se refiere a los soldados integrados en dicha unidad militar, solamente tenemos conocimiento de un oficial de la misma, el prefecto ......Graniano, natural de Faventia, es decir de la colonia Iulia Faventia Augusta Pia Barcinonensis (actual Barcelona) y, en consecuencia, de origen hispano.

Junto a ello el diploma militar del año 145 hace mención del único soldado de este destacamento de tropas cuyo nombre conocemos, ....entis f(ilius) Iustus, cuya denominación de origen, ex castris, lo identifica igualmente como hijo de soldado ${ }^{39}$.

\section{EL FINAL DE LA UNIDAD}

Difícilmente podemos constatar el momento de desaparición de esta unidad militar de astures y galaicos; sin embargo, aunque no disponemos de ningún documento que nos permita aproximarnos a una fecha concreta, es posible que no desapareciese antes de los años finales del siglo II.

36 CIL III.10674. Cf. J.M.ROLDÁN, Hispania y el ejército romano, p.95.

37 E.SWOBODA, "Der pannonische Limes und sein Vorland", Carnuntum Jahrbücher 1959, pp. 17 y ss.

38 Ver, entre otros, B.LÖRINCZ, "Zue Erbauung des Legionslagers von Brigetio", AArchHung 27 (1975) 343 y ss. Más detalles en E.SWOBODA, "Trajan und der pannonische Limes", Les empereurs romains d'Espagne, París 1965, pp.195 y ss.

39 Sobre los problemas derivados de este tipo de denominaciones ver, entre otros, F. VITTINGHOFF, "Die rechtliche Stellung der canabae legionis und die Herkunftsgabe castris", Chiron 1 (1971) 299 y ss. 
Es más, creemos que su existencia se prolongaría durante algunas décadas de la centuria siguiente, momento en el que ya no se elaboran los diplomas militares que podrían haber testimoniado su existencia. 